\title{
ESTADO, MERCADO E OUTRAS INSTITUIÇÕES REGULADORAS
}

\author{
REGINALDO MORAES
}

Uma volumosa literatura recente aponta a globalização financeira como fenômeno inevitável, irreversível e unívoco. Uma simples inspeção bastaria para identificar alguns de seus lugares comuns, muitos dos quais têm tido intensa repercussão entre estudiosos, no jornalismo especializado e nas falas dos atores políticos. Dois desses temas (e lemas) merecem destaque, sobretudo porque contribuem para delimitar uma problemática:

- as instituições políticas nacionais tornaram-se ineficazes, pesadas, nocivas - o poder de fogo do Estado nacional definha;

- dentro desses estados, os partidos políticos construídos a partir de ideologias e programas perdem espaço para outras formas de organização e ação política (pontuais, setoriais) ou, quando e onde sobrevivem, esses partidos (e os governos que eles constituem) são dirigidos por resultados estritos e pasteurizados, por um pragmatismo que se molda pelas preferências do eleitor medio, este também rigidamente orientado por resultados de curto prazo.

Ainda que tais idéias estejam muito longe de serem novas, podese dizer que elas começaram a ganhar notoriedade nos anos $70 .{ }^{1}$

${ }^{1}$ Há certamente razões para essa ascensão. Uma delas é sugerida por uma analista à qual retornaremos mais diante. "When I said there was little understanding of Keynesian logic in the 1930s, I should have added that in the 1930s and in the 1940s there were, however, the necessary and sufficient conditions for governments to apply that logic within national economies. This is worth noting because those conditions are no longer there. One was the low level of capital mobility. (...) By the mid-1980s, the old insulating fences around most national economies were gone" (Strange, 1998, p.91). Cf. também, sobre a caracterização desse momento da economia internacional: Cohen, 1996 e Goodman e Pauly, 1993. Para uma visão mais de longo prazo sobre a evolução da ordem (ou desordem...) econômica mundial, ver Block, 1980 e Helleiner, 1994.[NR: Todas as referências completas da bibliografia citada nas notas encontram-se nas "Referências Bibliográficas", no final do artigo]. 
Emblemática a esse respeito é a concessão do prêmio Nobel de Economia em 1974, dividido entre Gunnar Myrdal, o keynesiano e social-democrata sueco, e von Hayek, o patrono do neoliberalismo e do fundamentalismo de mercado. Também significativo, nesse momento, é o relatório da Comissão Trilateral $^{2}$ denunciando a ingovernabilidade das democracias, tema que pautou numerosos debates nos anos seguintes; A supremacia liberal tornase mais clara no início dos 80, quando o pensamento econômico do World Bank é penetrado pela Public Choice School e pelas teorias da "rent-seeking society". 3

O clímax desse ideário talvez possa ser apontado no fim dos anos $80^{4}$. $\mathrm{O}$ fantasma comunista parecia exorcizado, com a queda do muro de Berlim e a desagregação do império soviético. E tornando concreta enfim à pregação de Hayek (Caminho da Servidão, em 1944), segundo a qual os propósitos de reforma social constituíam apenas a forma envergonhada e parcial da revolução totalitária, os alvos prediletos da chamada Nova Direita passaram a ser a social-democracia, o keynesianismo, o Welfare State, as tentativas, em suma, de "civilizar" o mercado. No espaço latino-americano, esse papel - satânico, para uns, civilizador, para outros teria sido representado pelas ideologias nacional-desenvolvimentistas ou "estatistas". A essa figuras políticas passaram a ser imputados os grandes males do mundo contemporâneo: inflação galopante, desequilíbrio fiscal, gasto público descontrolado, endividamento. São bastante conhecidas as soluções apontadas para tais danos: reduzir o aparelho e a ação do Estado, submeter praticamente todos os nichos da vida social aos condicionamentos e disciplinas do mercado, abrir as economias reguladas e protegidas à saneadora competição internacional.

Contudo, passado algum tempo, mesmo as instituições que protagonizaram essa ofensiva reformadora fazem um balanço bem menos otimista dos ajustes. Já no fim de 1999, FMI e Banco Mundial - e

${ }^{3}$ No início dos anos 80, o economista-chefe do Banco Mundial, Hollis Chenery, um "desenvolvimentista" doutorado em Harvard, foi substituído, na direção do departamento de pesquisa do banco, por Anne Krueger, liberal entusiasta, vinda da Universidade de Minesota e uma das criadoras da teoria da rent-seeking. Vale lembrar o comentário elegante e "diplomático" de J. Stiglitz sobre a diferença entre os dois: "Hollis Chenery, say, on the one hand, representing the modern evolution of the planning approach, and Anne Krueger, say, on the other hand, focusing on the reliance of market mechanisms" (Stiglitz, 1999). Para uma referência fundante da teoria da "rent-seeking", ver Krueger, 1974. Para conhecer aplicações dessa perspectiva ao exame dos países subdesenvolvidos, ver Krueger, 1993.

4 Para uma história da formação e ascensão dos movimentos e organizações neoconservadoras na Inglaterra, cf. Cockett, 1995. Para o mesmo tema, mas nos EUA, ver Nash, 1996 e também Smith, 1991. 
escritores outrora francamente neoliberais, como John Gray5 -- reconhecem que suas receitas não levaram ao desenvolvimento econômico que esperavam, gerando, além disso, efeitos inesperados (?) e indesejados(?) como o aumento da desigualdade social, a exclusão e a marginalidade, a especulação financeira desenfreada, o ressurgimento de movimentos ideológicos racistas, conflitos étnicos e assim por diante. É conhecida ainda a crítica do economista-chefe do Banco Mundial, J. Stiglitz ${ }^{7}$, aos programas de ajuste e particularmente às estratégias do $\mathrm{FMI}^{8}$. Curiosamente, porém, esses insucessos ou dificuldades não trouxeram à baila, novamente, programas políticos de esquerda, social-democratas ou comunistas. Pelo contrário, estes antigos projetos continuaram e continuam a ser vistos, inclusive pelos partidos de esquerda "renovados", como definitivamente superados pelos eventos e como incapazes de gerenciar o futuro, o qual se costuma apresentar como "inevitavelmente globalizado".

Para este último termo devemos dar atenção redobrada, porque a noção de globalização, ainda que de diferentes modos entendida, parece balizar justamente tais juízos e avaliações de viabilidade, ou seja, parece determinar as dimensões das "possibilidades objetivas". A suposta inevitabilidade da globalização aparece, não raro, como um diagnóstico aparentemente neutro, que permeia discursos de muito diferentes origens e muito diferentes quadrantes ideológicos. A partir de tal enquadramento, a política que se faz nos marcos nacionais parece cada vez mais ineficaz e impotente. Regulações econômicas, legislação trabalhista, estruturas de bem-estar social, gasto público - tudo isso parece definitivamente constrangido por aquilo que julgam aceitável os mercados financeiros, voláteis, caprichosos e imperativos. A luta política no interior dos estados nacionais parece cada vez mais "desideologizada" e limitada a um leque de escolhas monotônico. ${ }^{9} \mathrm{Na}$ verdade, parece não haver propriamente um leque, mas uma linha, uma "linha justa", poderíamos dizer, se outro fosse o jargão dominante: não há salvação fora da globalização - e dentro dela não há escolhas, há mandamentos.

A crer em tal tipo de arrazoado, estaríamos portanto vivendo a obsoletização das coalizações políticas e sociais industrialistas, desen-

5 Gray, 1993 e 1997. Ver ainda, Gray, 1999.

6 Verdade que caberia ponderar se de fato seriam inesperados e/ou indesejados.

7 Stiglitz, 1998. Ver também Stiglitz, 2000. Existe ainda uma versão condensada do argumento de Stiglitz, publicado na Folha de S. Paulo, 12 de julho de 1998, Caderno Mais!

8 Como se sabe, esse ângulo de análise foi acentuado no relatório anual do Banco, de 2001, com ênfase na questão da pobreza.

9 Note-se aqui, ainda uma vez, a conexão entre os dois temas sublinhados no início deste texto 
volvimentistas ou "welfaristas" que teriam construído a história e a fisionomia do pós-guerra. Como dissemos, uma parte do pensamento reformador, de esquerda, parece ter aceito esta embocadura.. Para esta visão, o papel do governo é tornar suas sociedades competitivas, o que se conseguiria com infra-estrutura (física e institucional) amigável para os capitais privados e, de quebra, força de trabalho razoavelmente treinada, flexível e cooperativa. Nesse enredo, os capitais - analogamente às massas humanas dos últimos séculos - "votam com os pés" e os países reproduzem, no plano internacional, mecanismos similares à guerra fiscal, vigorante nas relações entre governos subnacionais. Isto valeria também para outros expedientes voltados à atração de investidores.

\section{O TOM DA CRÍTICA}

Há contudo quem afirme a existência de exageros e equívocos nesse tipo de juízo sobre a realidade e suas tendências. Segundo os críticos, entre as realidades exageradas figura, com distinção, exatamente esta a que se aludiu acima, a que afirma a obsolescência dos estados nacionais e da política que se faz no seu interior. A rigor, a crítica encontraria estímulo até mesmo nos discursos que procura criticar. Quem lê, por exemplo, o relatório do World Bank sobre "o Estado num mundo em transformação" (1997) fica incomodado com um paradoxo. Os países aos quais se recomenda o pacote de reformas são qualificados como portadores de instituições "fracas" ou "viciadas", que teriam gerado poderosos obstáculos à inovação, ao dinamismo, à equidade, a tudo aquilo enfim que faz ou fez a virtude das sociedades modernas (aquelas desde há muito moldadas pelo mercado livre). Ao mesmo tempo, e também por isso, o pacote de reformas recomendado no report é, a toda prova, uma obra para semideuses - exige um conjunto de instituições (e um Estado) simplesmente hercúleo.

Entre os exageros da nova retórica, em suma, está o tamanho da dita "globalização" e do transbordamento dos bs nacionais. Alguns estudos ${ }^{10}$ já apontaram para isso, com fartos indicadores quantitativos. Segundo tais análises e dados, a economia mundial continua embasada, fundamentalmente, em produtos gerados pelos e para os mercados nacionais. Continua sendo dirigida por forças competitivas interiorizadas em espaços nacionais.

10 Cf. por exemplo: Hirst e Thompson, 1999; Wade, 1996. Cf. ainda Weiss, 1998. Entre nós, uma avaliação compreensiva do problema e da literatura está em Batista Jr., 2000 (parte 1). 
Continua sendo constrangida (ou impulsionada) por instituições que se constróem no plano dos estados nacionais. As empresas - ainda aquelas que operam num espaço econômico "internacionalizado" - têm de se valer (e efetivamente tiram partido) de redes e vínculos com governos nacionais e subnacionais, com associações empresariais e fornecedores também erguidas nesses níveis, com regulamentos, padrões e normas que restringem (e garantem) seus direitos de propriedade, de uso de recursos (inclusive propriedade e recursos intelectuais, como as inovações técnicas), com os mecanismos formadores e disciplinadores de força de trabalho construídos também nesses níveis, os níveis do Estado-nação e dos governos subnacionais ${ }^{11}$. Isto valeria, digamos, para a Ford Company, no Brasil, como valeria, mutatis mutandis, para as pequenas e médias empresas na "terceira Itália".

Interessa aos grandes conglomerados e corporações um mundo de mercados globais verdadeiramente desregulamentados, no que diz respeito a finanças e moedas? Os críticos apontam que nada indica tal certeza - e a ordem reconstruída do pós-guerra parece confirmar essa impressão ${ }^{12}$. Regras mais ou menos estabelecidas e previsíveis para o comércio, legislação relativa a direitos de propriedade, uso e transferência de tecnologia, taxas de câmbio relativamente estáveis e confiáveis - tudo isso faz parte das condições de existência da grande corporação, para quem, como se sabe, é regra o planejamento, e não a volatilidade e a incerteza. E para essa ordem internacional, os estados nacionais são ainda decisivos.

Suponhamos como aceite a expectativa de um mundo mais complexo, mais integrado (interdependente seria um termo mais adequado) e ao mesmo tempo mais diversificado, mais competitivo, etc. Ainda assim, seria difícil imaginá-lo como um mundo com menos regras - se não se quiser aportar a uma selva de conflitos destrutivos, a um jogo imune a qualquer previsão (a não ser, é claro, a previsão de um apocalipse). Em uma palavra, se não se quiser retornar à guerra de todos contra todos pressagiada na famosa passagem de Hobbes:

“... tudo aquilo que é se pode atribuir ao tempo de guerra, em que todo homem é inimigo de todo homem, pode-se também dizer do tempo durante o qual os homens vivem sem outra segurança senão a que lhes pode ser oferecida por sua própria força e seu próprio engenho. Numa tal situação, não há lugar para a indústria, pois seu fruto é incerto; conseqüente-

11 Remeto a curioso artigo de Antonio Delfim Netto na Folha de S. Paulo, p. 2, 11 de outubro de 2000.

${ }^{12}$ A esse respeito, cf. os trabalhos já citados de Block e Helleiner. Também o estudo de Eichengreen, 2000 dá indicações nesse sentido. 
mente não há cultivo da terra, nem navegação, nem uso das mercadorias que podem ser importadas pelo mar; não há construções confortáveis, nem instrumentos para mover e remover as coisas que precisam de grande força; não há conhecimento da face da Terra, nem cômputo do tempo, nem artes, nem letras, nem sociedade; e o que é pior do que tudo, não há senão um constante temor e perigo de morte violenta. $\mathrm{E}$ a vida do homem é solitária, pobre, sórdida, embrutecida e curta." (Leviatã, cap. XIII) ${ }^{13}$

\section{O ESTADO E AS FORMAS DO ESPAÇO PÚBLICO (Dois eixos temáticos para a reflexão crítica)}

Para essa ordem internacional, os estados nacionais são ainda decisivos, repita-se. Mas há estados e estados. Nem todos são iguais, nem todos são igualmente significativos, nem todos sobreviverão. Alguns serão estados, outros apenas seguirão estando. E, de fato, uns e outros desses estados têm passado, passam e passarão necessariamente por significativas transformações. Entre estas últimas figuram, sim, o surgimento de novas formas de verbalização e representação de interesses, de formulação de políticas e de regras operativas, de participação e identidade. Mas... desaparecerá com isso a democracia representativa, a democracia dos partidos, das ideologias e dos parlamentos? A anunciada, nova e singular microfísica do poder substituirá esses grandes núcleos de gravitação por um policentrismo, um círculo que a todos envolve, mas cujo centro está em todo ponto e nenhum?

Retomemos em outro registro a reflexão sobre esse problema. $\mathrm{O}$ governo representativo - na formulação liberal-democrática - tem formas definidas de formulação de políticas, verbalização e representação de interesses, bem como de seus controles de comportamento (accountability). Chamemo-lo de primeiro circuito, aquele em que a cidadania votante constitui os três poderes do estado: legislaturas, tribunais, executivos. Há mais de um século, contudo, este quadro vem sendo complicado pela evidente e progressiva expansão das atividades do estado (e mais do executivo, propriamente) - tanto em escala quanto em escopo ${ }^{14}$. Isto trouxe também à

13 Sublinhemos. Como se sabe, este quadro deletério é parte determinande do argumento hobbesinao justificando a constituição de uma soberania plena e indivisa - a do Estado-Leviatã. 14 Ver, de Shonfield, Capitalismo Moderno, parte IV: "Implicações políticas do princípio do governo ativo". Ou Landauer, 1966, vol. 1, cap. 10. 
cena formas outras de encarnação daquelas funções políticas ${ }^{15}$, um segundo circuito composto de corporações, conselhos técnicos, autarquias, organizações não-governamentais, um variado conjunto, enfim, de figuras de direito privado ou semi-privado que recebem delegação de poder público, ordenando relações sociais, produzindo normas e quase-leis, atuando como tribunais administrativos, assumindo a execução de políticas públicas, atuando como conectores de instituições privadas, movimentos sociais, etc.

Estas figuras novas (ou renovadas) da vida política colocam o problema de redefinição da "forma Estado" ou dos vínculos entre instituições sociais e instâncias políticas de representação e decisão. As regras de atuação dessas figuras não estão, em geral, previstas na constituição do Estado -- não, pelo menos, como está prevista a constituição do primeiro circuito, aquele típico da democracia representativa. Suas regras operatórias são estabelecidas "em situação", derivando de práticas, usos, costumes... e dos pesos específicos que aí assumem. Não estão elas na esfera estatal - mas também seria abusivo incluí-las, pura e simplesmente, entre as instituições privadas, como as empresas comerciais, por exemplo. $\mathrm{O}$ pensamento liberal tende a incluí-las no universo da espontaneidade ou, mais propriamente, como aquilo que é criado pela ação humana mas não pela deliberação humana, para utilizar a célebre fórmula do iluminista escocês Adam Ferguson. Isto é, contudo, problemático: elas têm uma relação decisiva com o universo do direito e das regras formais produzidas pela deliberação. E muitas delas estão longe de serem propriamente espontâneas ou não-deliberadamente construídas ${ }^{16}$. A história recente dos estados modernos é marcada pela incorporação empírica desses organismos no corpo político do Estado e pela ação reguladora/cooptadora deste último.

Em suma, existe algo mais entre Estado e mercado (ou entre Estado e sociedade civil) do que podem supor as nossas vãs dicotomias.

Algumas questões servem como indicador de tal complexidade. Se organismos desse tipo recebem fundos públicos ou realizam atividades delegadas pelo poder público, como poderiam estar colocadas fora do

15 Cabe menção a pelo menos alguns estudos dessa conexão decisiva (ou até mesmo derivação) entre o crescimento da agenda do Estado e as modificações de suas estruturas. Refiro-me a Claus Offe. Além dos ensaios contidos em Capitalismo desorganizado (1989), ver também "Democracia partidária competitiva e o "Welfare State" keynesiano: fatores de estabilidade e desorganização", em Problemas Estruturais do Estado Capitalista; e "El corporativismo como um sistema de estructuracion global, no político, de la sociedade?" (1992). 16 Ver também, a esse respeito, os "modes of governance" examinados por Boyer e Hollingsworth em "Coordination of economic actors and social systems of production", in Hollingsworth e Boyer (eds), 1997. Ver ainda, no mesmo volume, Hollingsworth e Boyer, "From National Embeddedness to Spatial and Institutional Nestedness". 
âmbito público e fora da esfera de controle do Estado? Alguma forma de regulação e accountability tem que ser prevista para elas. Alguma solução tem de ser encontrada, ainda, para o fato de tais figuras promoverem ou suporem formas de exclusão (dos não organizados e dos não organizáveis, dos debilmente organizáveis).

Ora, ainda que o velho Estado e a velha política sejam substituídos por essa nova configuração, pluralista ou policêntrica, sobrevive aquilo que se continuará chamando de esfera pública ou de poder público, um espaço no interior do qual e através do qual se assegura o compartilhamento de certas regras de convivência e se evita e sanciona o comportamento oportunista ou free rider. Em suma: parece inarredável a existência de um espaço em que resta alguma forma clara e perceptível de imposição, aos recalcitrantes, dos padrões aceitos pelos parceiros da ordem. Uma coisa é afirmar que muda a forma dessa esfera pública. Outra, bem diferente, é dizer que ela se resolve ou dissolve em esferas privadas ou segmentadas, quase-privadas, constituídas por "tribos", "famílias" ou "hordas". A primeira dessas afirmações formula um problema urgente e relevante, um programa complexo para a teoria e a prática da política democrática - incluindo a necessidade de definir modos legítimos de seleção dos participantes nos diferentes fóruns decisórios, suas formas de accountability, o peso relativo dos "votos e vetos" de cada segmento organizado, etc.. A segunda afirmação é mais sibilina. Na verdade, oculta a formulação do problema - ou declara a sua inutilidade, dada a "falência" ou inoperância do espaço político nacional, do Estado nacional. Graças a essa ocultação, corre o risco de facilitar o contrabando, na penumbra, de uma solução bastante peculiar, uma autocracia estabelecida pelo silêncio, pela imposição tácita: a estranha, embora conhecida, ditadura dos mercados financeiros ${ }^{17}$. Por isso, repita-se, parece-nos que vale a pena encampar a primeira afirmação - e o programa de pesquisa ali envolvido. Ou seja: muda a forma da esfera pública, mas ela não se resolve nem se dissolve em esferas privadas ou segmentadas, quase-privadas, constituídas por "tribos", "famílias" ou "hordas". Isto constitui um problema urgente e relevante. E, ainda uma vez repetindo, daí deriva um programa complexo para a teoria e a prática da política democrática - incluindo a necessidade de definir modos legítimos de seleção dos participantes nos diferentes fóruns decisórios, suas formas de accountability, o peso relativo dos "votos e

17 Avaliação bastante crítica dessa evolução pode ser vista em Greider, 1993. Greider (1998) expande o argumento (ver principalmente os capítulos 1 e 11). 
vetos" de cada segmento organizado, etc.. Talvez se deva aqui fazer um esclarecimento que evite interpretações que não pretendemos estimular. Quando se diz que das considerações anteriores resulta um programa complexo para a teoria e a prática, não se diz que a teoria deva necessariamente regrar a prática, produzir necessariamente conclusões normativas. Disso resulta um programa complexo para a prática dos agentes - e, portanto, um problema a mais para ser considerado e compreendido pela teoria enquanto teoria.

Este item pode ser parte do projeto - ambicioso, exigente e complexo - de uma nova teoria das instituições democráticas, ou de uma reinvenção dessas instituições.

\section{A INCERTEZA E A DIMENSÃO INTERNACIONAL (Terceiro eixo temático para a reflexão crítica)}

Antes de dar seguimento, cabe contudo chamar atenção para uma componente da análise, a dimensão internacional, ainda que preventivamente. Mesmo que o seu exame circunstanciado seja ainda mais ambicioso e complexo do que o anteriormente exposto, esta coordenada deve, pelo menos e desde logo, ter sua existência considerada. Ela nos levaria a moderar os rancores do extremismo neoliberal e contemplar com mais cuidado os trabalhos de história econômica e das instituições que têm posto em questão padrões interpretativos "naturalizantes" inspirados na economia neoclássica. 18

Apenas desse modo, parece-nos, poderíamos compreender, por exemplo, experiências como as do planejamento indicativo, na França, ou do New Deal rooseveltiano. Em grande medida, temos, nesses experimentos, arranjos sócio-políticos em que empreendedores de vários ramos são

\footnotetext{
18 Evidentemente, isso traz à tona, novamente, o tema da colonização das ciências sociais pelos modelos cunhados nas ciências físicas. Felizmente, nesse rumo, uma tradição recente mas já afirmada procura examinar as respostas historicamente aventadas para o problema da presença, no mundo social, dos princípios de incerteza, complexidade e indeterminação. As referências aqui sugeridas são variadas e de múltiplas orientações, conforme pudemos constatar em leitura que tentou se livrar de pré-juízos classificatórios e excludentes. As referências dizem respeito, evidentemente, às sendas abertas por Robert Coase, desde os anos 1930, e por Oliver Williamson, em tempos mais recentes. Mas também apontam para autores próximos da escola francesa da regulação e da "análise econômica das convenções", notadamente para os trabalhos de Robert Boyer e André Orléan. Ou ainda para as tentativas de Geoffrey Hodgson e William Lazonick no sentido de desenhar análises institucionalistas com perfil próprio. Como dissemos, são referências oriundas de vertentes bastante diversas das ciências sociais.
} 
encorajados, sob a coordenação e estímulo de agências governamentais, a concertar seus planos de produção para um certo número de anos. Isto às vezes aparecia aos agentes em situação - tacitamente ou não, no momento não nos importa - como substituto para mercados intertemporais inexistentes ou, sublinhe-se, com baixa probabilidade de vir a existir. Tais procedimentos poderiam garantir alguma previsibilidade para certos empreendimentos e fazer com que alguns empreendedores ganhassem em escala e velocidade, bem como apostassem em pesquisa e desenvolvimento de retorno mais lento, por exemplo. Em suma, esses procedimentos e arranjos afetavam várias externalidades e incertezas - com importantes conseqüências para as ações econômicas.

O mesmo (ou algo semelhante, pelo menos) não se poderia dizer para enquadrar teoricamente os contratos privados intertemporais, envolvendo alguma espécie de integração vertical ou horizontal de empresas? Citemos como exemplo: contratos mais ou menos estáveis de fornecimento (incluindo o de força de trabalho - os acertos de longo prazo com sindicatos), protegidos por um forte e onipresente sistema judiciário e apólices de seguros, etc. ${ }^{19}$

Em suma, o que pretendo é sublinhar as diferentes respostas dadas ao problema dos mercados intertemporais, do risco e da incerteza. Em outras palavras, devemos olhar com atenção para as instituições criadas - nos planos internacional e doméstico -- para enfrentar tais desafios. A reflexão ganha ainda mais atualidade, quando se evidencia o aspecto problemático e instabilizador da solução mais reverenciada dos últimos anos, ou, para ser mais preciso, com aquilo que se caracteriza ou caracterizava como solução para tais incertezas. Refiro-me à existência de um mercado financeiro desregulamentado e de moedas virtuais que estão vinte e quatro horas no ar graças às festejadas maravilhas da eletrônica - instituições que dependeram de mutações não deliberadas (e cumulativas) mas, também, da ação deliberada (e decisiva) de atores políticos de grande porte, sediados sobretudo nos estados nacionais que lideram a economia do ocidente $^{20}$. E aqui, exatamente, devemos conectar esta nota final com a anterior reflexão a respeito dos sinais de obsolescência do Estado nacional.

19 Este processo, que inclui o modo como corporações suspendem, controlam ou suplantam o mercado, é resumido no capítulo IV do livro de G. Arrighi (1996), explorando trabalhos de R. Coase, Alfred Chandler, Oliver Williamson e, sobretudo, do Galbraith de O Novo Estado Industrial.

${ }^{20}$ Este é um tema enfatizado no estudo de Eric Helleiner, já citado 
Resta saber se atualmente - com as mutações e limites impostos aos estados nacionais - resta algum espaço para algo como o planejamento indicativo, o New Deal, as câmaras setoriais, as políticas industriais, etc. - ou se análogos ou sucedâneos de tais procedimentos têm de ser pensados, agora, em uma estratégia que compreenda, desde logo, um nível internacional ${ }^{21}$. Este é, me parece, um desafio que se soma à supramencionada carência de uma nova teoria das instituições democráticas. E viria a constituir o seu terceiro eixo temático.

\section{Algumas questões mais delimitadas e pontuais}

Para precisar um pouco mais estas perguntas de curto prazo, talvez seja produtivo explorar aquilo que chamamos de segundo eixo.

Algumas dessas questões podem ser assim resumidas:

- Qual a relação entre as instituições clássicas da democracia representativa e as "formas novas" de vocalização e representação de interesses, tais como: (a) os "novos movimentos sociais"; (b) as organizações não-estatais ou não-governamentais?

- Quais as atividades sociais que, nesse novo quadro, ainda permanecem no horizonte e na esfera de competência das instituições estatais convencionais?

- Quais as atividades que são transferidas para as "novas" instituições?

Como se recolocaria a questão do monopólio do Estado, ou, antes, dos três monopólios básicos que têm configurado sua existência: coleta e gestão do excedente econômico que demanda gerenciamento coletivo; produção e distribuição do direito; uso legítimo da coerção?

Quais os fóruns de reconhecimento e legitimação das "novas formas" de representação, etc.? Quais os critérios para definir seus "preços relativos", ou a quantidade de "votos" que cada uma delas tem nos espaços de decisão sobre os bens públicos?

21 Voltamos desse modo ao comentário já referido de Susan Strange, em Mad Money, agora lendo (e grifando) uma frase que deliberadamente omitimos na citação anterior, no início deste texto: "When I said there was little understanding of keynesian logic in the 1930s, I should have added that in the 1930s and in the 1940s there were, however, the necessary and sufficient conditions for governments to apply that logic within national economies. This is worth noting because those conditions are no longer there. One was the low level of capital mobility. (...) By the mid-1980s, the old insulating fences around most national economies were gone. The logic of the General Theory still held. But henceforth if counter-cyclical intervention were to be effective, it would have to be global and collective, not national. (p. 91) 
Desdobrando o anterior a partir dos artigos já mencionados de Claus Offe, as "novas formas" têm uma derivação histórica ou estruturalmente determinada:

- crescimento das atividades empreendidas pelo Estado (regulação econômica, políticas sociais, investimento infra-estrutural, etc.);

- incapacidade, para gerir as novas manifestações de vontades e interesses daí nascentes, do sistema eletivo definido com base na representação territorial (partidos, assembléias, congressos, etc.).

As "novas formas" constituem portanto soluções para um problema. Geram contudo, elas mesmas, um outro problema. A atribuição de estatuto político aos grupos de interesse e similares significa o reconhecimento, ao lado das autoridades legalmente constituídas, de autoridades paralegalmente constituídas. Esse reconhecimento (permissão para ingressar, opinar e votar em fóruns decisórios de políticas públicas) se dá (se impõe) espontânea ou tacitamente. Coloca-se o problema da legitimação dessas inclusões (quais devem ser reconhecidas) e de seus pesos relativos (quantos votos cada uma delas tem, no fórum de que legitimamente participa).

Se organismos desse tipo recebem fundos públicos ou realizam atividades delegadas pelo poder público, é problemático pensá-las fora do âmbito público e fora da esfera de controle do Estado, se por este (a esfera do Estado) entendemos o pacto social mais compreensivo, de maior amplitude. Quais as formas de regulagem, disciplinamento e accountability por elas e para elas previstas?22

Como se coloca o fato de tais figuras promoverem ou suporem exclusões (os não organizados e os não organizáveis, os debilmente organizáveis)?

Quanto à consideração do contexto, cláusula importante nos procedimentos que deveríamos adotar neste estudo, cabe reconhecer que, à primeira vista, ela traz mais paradoxo do que compreensão. Exemplifico e explico a seguir.

Veja-se o caso dos pluralistas e corporativistas dos anos 1920/30, como Harold Laski, G.D. H. Cole, Mihail Manoilesco, etc.

Os autores que trataram de examinar, retrospectivamente, as

22 A frase de Dahl, para resumir o problema, é esta: "Like individuals, then, organizations ought to possess some autonomy, and at the same time they should also be controlled" (Dillemas of pluralist democracy, 1982, p. 1) 
instituições que Laski, Cole e Manoilesco viam nascer - e para a qual propunham estatuto de legitimidade - destacaram exatamente os determinantes contextuais desse nascimento. Como dissemos, nos ensaios já acima citados, Claus Offe, por exemplo, enfatiza que o crescimento das atividades do Estado (política econômica, intervencionismo, políticas sociais, etc.) trazia, implicava e/ou pressupunha também novas formas de verbalização e representação de interesses. Shonfield tratou isso em um capítulo conclusivo de seu importante livro, Capitalismo Moderno: "As implicações políticas do principio do governo ativo". Em outro quadrante teórico e ideológico, as mutações do conceito de cidadania e representação constituem, igualmente, o tema de conhecido estudo de Carl Landauer, no capítulo 10 de seu Sistemas Econômicos Contemporâneos.

Esse é, ao que parece, o quadro envolvente do pluralismo e do corporativismo que se desenvolve a partir dos anos 20 (sobretudo na Europa). Em certa medida, também é o caso das teorias pluralistas que estudam os grupos de interesse nos EUA dos anos 50/60 (Dahl, por exemplo, no seu Who governs?). Uma pergunta central que aí se tenta responder é essa: como se resolvem, explicam e determinam as políticas publicas com a presença dos grupos de interesse e do big government do pós-II Guerra?

Qual o cenário que se tenta explicar, nessas elaborações? É este: as mutações detectadas na democracia liberal e nas suas formas de verbalização e representação de interesses, aferição e agregação de preferências (partidos, parlamentos), diante da presença cada vez maior do poder público (estatal) na regulação das atividades sociais, econômicas, etc.

Em outros e breves termos, o contexto aparente é esse: afirmação de grupos de interesse, associações, corporações (e teorias sobre elas) no quadro de expansão do Estado, intervencionismo, planejamento, políticas sociais, etc

Pois bem. Agora, vejamos a reflexão sobre o pluralismo desenvolvida por autores mais recentes como Paul Hirst e o que poderíamos chamar de segundo Dahl (os textos posteriores a Who Governs?).

$\mathrm{O}$ enquadramento contextual, quanto às dimensões e presença do Estado, é outro e no entanto o resultado parece similar (sobrevivência, florescimento dos grupos, como conclusão descritiva; conveniência desse florescimento, como conclusão normativa). Talvez aqui se possa inverter a sentença anterior: a afirmação de grupos de interesse, associações, corporações (e teorias sobre elas) dá-se no quadro de retração, esvaziamento e mesmo (segundo alguns) morte do Estado nacional, do intervencionismo, do planejamento, das políticas sociais, etc. 
Em suma, como é que se recoloca aquela formulação acima, quanto ao cenário que se tenta explicar? A sentença, modificada, seria mais ou menos esta: "Mutações detectadas na democracia liberal e nas suas formas de verbalização e representação de interesses, aferição e agregação de preferências (partidos, parlamentos), diante da presença cada vez maior (menor?) do poder público (estatal) na regulagem das atividades sociais, econômicas, etc...".

São dois momentos interessantes portanto, da história das idéias e da história das instituições. Não nos parece que de seu entendimento resulte apenas um estudo sobre a história do pensamento político. É também isso e já não é pouco. Mas é, igualmente, um estudo sobre o tipo de resposta político-prática, institucional, que se dá a um problema bastante atual.

\section{CAMINHOS E PROCEDIMENTOS}

As proposições dos pluralistas a que temos feito referência - na medida em que respondem às questões acima listadas ou sugeridas - constituem importante referência para a reflexão. Importa, então, reconsiderar as razões e imagens que compõem o seu argumento.

Mas nesse estudo ainda um cuidado se deve ter: o enquadramento contextual. Este deve ser entendido também como a consideração dos argumentos contra os quais esses autores se colocam. Considerar o contexto significa portanto verificar não apenas a partir de qual ponto ou rede de eventos e significados eles falam, mas também contra quais vetores (nos planos dos eventos e das idéias) eles se movem.

Também na direção apontada pelo parágrafo anterior, duas advertências devem ser feitas.

$\left(1^{\circ}\right)$ Em primeiro lugar, o exame da argumentação de Hirst e Dahl tem, com certeza, pela própria definição do campo teórico em que operam e do papel prático-político que esperam para seu discurso, implicações que transcendem a chamada análise intrínseca ou imanente. Em especial, é preciso estar atento à recepção de seus temas no debate recente a respeito de questões como a reforma do Estado e modificações do espaço público, debate que se verifica, igualmente, no campo conceitual e no campo das proposições políticas. Os temas em que tal debate se incorpora são conhecidos: a presença das "organizações sociais" no novo desenho do Estado, a substituição de entidades estatais por entidades privadas, cooperativas ou do "terceiro setor" na prestação de serviços públicos, a geração 
de agências reguladoras igualmente híbridas (ou anfíbias) como correlato necessário da privatização de empresas estatais, as transformações (e interpenetrações) do Direito Público e Direito Privado, como respostas ou antecipações ao novo mundo das market oriented reforms.

Em certo momento de Associative Democracy, Hirst afirma que as novas formas de economic and social governance lançam uma ponte entre sociedade civil e Estado, transformando essa divisão: elas caminhariam no sentido de pluralizar o Estado (diversificando os canais que geram e executam normas, por exemplo) e, em contrapartida, de publicizar a sociedade civil, evitando que esta seja um compósito de guetos corporativos insulados e pouco transparentes. Pensemos agora, saindo da letra de Hirst, nas diferentes manifestações dessas novas formas nos três poderes do Estado (porque elas se manifestam nos três poderes). Fóruns de desenvolvimento e câmaras setoriais geram normas e quase-leis (tributárias, creditícias, ambientais, trabalhistas, entre outras) - colocando-se ao lado das instâncias legislativas. Repartições estatais, divisões do executivo, são substituídas ou complementadas, na aplicação de políticas públicas, por agências privadas ou cooperativas, conselhos gestores híbridos, etc. No terreno do poder judiciário, mecanismos de consulta e arbitragem são criados para examinar conflitos, produzir acordos e sentenças e desafogar os tribunais.

Voltando à formulação generalizadora de Hirst, essa ponte entre Estado e sociedade civil pode redundar numa pluralização do Estado e numa publicização da sociedade. Mas, como também apontam Hirst e seu grupo ${ }^{23}$, pode também resultar na criação de um quango-state ${ }^{24}$ desprovido de qualquer forma de accountability. Esses potenciais - para o bem e para o mal justificam, por si sós, uma reflexão mais aprofundada sobre o tema. ${ }^{25}$

$\left(2^{\circ}\right)$ Ainda que tenhamos definido o mencionado "segundo eixo" de nossa descrição como centro e referência, o terceiro (a incerteza e a dimensão internacional) não pode deixar de ser considerado, ainda nesta etapa, como elemento condicionado e condicionante do segundo. Aliás, se voltarmos os olhos para trás, neste texto, ou seja, para a argumentação que introduz os nossos temas, poderemos verificar que em grande medida foi a partir do terceiro eixo que iniciamos o enquadramento dos demais. Ora, as

23 É um alarme repetido em Hirst e Khilnani (eds.): Reinventing Democracy, número especial do Political Quarterly, 1996). Também John Gray alerta seguidamente para esse risco cf.. os já referidos Endgames (cap. 1) e Falso amanhecer (cap. 2)

24 Quango, como se sabe, remete a "organizações quase não governamentais".

25 Examinando o "liberal-pluralismo" do Estado norte-emaricano (e da ciência política norteamericana) dos anos 60, Theodore J. Lowi esboçara um quadro daquilo que se poderia enquadrar nos referidos potenciais "para o mal". Ver seu The End of Liberalism (1969). 
reflexões sobre os novos desafios da teoria democrática e sobre a caracterização do espaço público, tal como delineadas por Dahl e Hirst, incidem, fundamentalmente, no espaço do Estado nacional. No caso de Hirst, é curioso que embora tenha assinado, em parceria com Grahame Thompson, um alentado e conhecido estudo sobre a globalização, nos seus ensaios a respeito das new forms of economic and social governance (subtítulo de Associative Democracy, de 1994) a dimensão internacional aparece muito mais como pano de fundo do que como protagonista ou coadjuvante da cena. A lacuna é reconsiderada, mais tarde, em From Statism to Pluralism (1997), em que a parte III é exatamente dedicada ao vínculo entre os dois planos. Quanto a Dahl, chega a limitar explicitamente a discussão sobre os Dilemmas of Pluralist Democracy (1982) ao plano do Estado nacional ${ }^{26}$. A resistência ou dificuldade na conexão dos dois temas pode constituir parte da explicação para o paradoxo que acima mencionamos. Lembremos o paradoxo, ainda que correndo o risco da repetição. Trata-se, por um lado, da afirmação de grupos de interesse, associações, corporações no quadro de expansão do Estado, intervencionismo, planejamento, políticas sociais - no momento em que se desenvolve o pluralismo de Laski e Cole, as teorias corporativistas de Manoilesco, etc. E, por outro lado, a afirmação de grupos de interesse, associações, corporações (e teorias sobre elas) no quadro de retração, esvaziamento e mesmo (segundo alguns) morte do Estado nacional, do intervencionismo, do planejamento, das políticas sociais, etc. - no momento em que se desenvolvem as modernas versões do pluralismo e do neocorporativismo.

Mas os temas - mais do que os autores - nos deveriam levar a pensar o espaço transnacional e os agentes transnacionais não mais (se é que um dia o foram) como componentes puramente "externos", mas como integrantes de um problema complexo e incerto pela sua própria natureza ${ }^{27}$. A relação entre organizações não governamentais e estados nacionais, por exemplo, passa a ser pensada de modo central, também,

26 Ver o capítulo 2 daquele livro, principalmente o item "The Country as the Largest Feasible Democratic Unit" (pp. 12-16)

27 Utilizo esses termos - incerteza e complexidade - propositadamente, para fazer menção a aspectos como a determinação recíproca e simultânea de diferentes "pedaços" da realidade social, o caráter reflexivo dessa mesma realidade, etc. Esses aspectos aparecem, em debates epistemológicos atuais, contestando a validade ou suficiência dos procedimentos analíticos (decomposição de problemas em partes simples e independentes) descritos magistralmente por Descartes no Discurso sobre o Método, nas Regras para a Direção do Espírito e nas Meditações de Filosofia Primeira. Para uma abordagem mais voltada a problemas de política internacional, vale consultar Jervis, Robert. System effects - Complexity in Political and Social Life (1998). 
quando se tematiza a sua incidência nas diversas organizações multilaterais, as quais se têm transformado, cada vez mais, em autoridades políticas para-estatais e supra-estatais que enquadram e regulam a "cidadania globalizada".28 Escritores "heréticos" têm insistido nessa relação e nas suas implicações para a intervenção política ${ }^{29}$. Mas, salvo engano e a despeito de eventuais desacordos com a opinião do autor, o delineamento do tema aparece de modo mais claro e conciso em estudo de David Held, Democracy and the global order ${ }^{30}$. Esta dimensão não pode ser ignorada nas reflexões sobre os dilemas da política democrática, ou da reinvenção da democracia.

Como se pode perceber, o que aqui se esboça é um projeto ou plano de investigação. Na forma alusiva e lacunar em que aqui se expõe, já se indica o quanto é complexo, ambicioso e exigente. Dizia o poeta que tudo vale a pena se a alma não é pequena. Ainda que não tenhamos descoberto o tamanho da nossa alma, pelo menos algo, se não tudo, deste projeto certamente vale a pena.

REGINALDO CARMELO MORAES é professor de Ciência Política no IFCH da Unicamp. Na mesma temática publicou Neoliberalismo - de onde vem, para onde vai? São Paulo, Editora SESC, 2001.

28 Lembremos os eventos registrados pelos meios de comunicação durante o Fórum Econômico de Davos, ou as reuniões de organismos multilaterais (como os do FMI e da OMC). A aparição das Organizações Não-Governamentais, antes (e repetidamente) apresentada como notável exemplo de solução pelos relatórios do Banco Mundial, é vista, agora, como um problema (ou pelo menos um sintoma de). Veja-se, por exemplo (e que exemplo!) o alerta lançado pelo conhecido editor do Financial Times, Martin Wolff, em "Lições do fracassado acordo sobre investimentos" (o artigo foi traduzido pela Gazeta Mercantil na sua edição de 16/9/99 - devo a referência a este exemplar artigo de Wolff a Sebastião Velasco e Cruz). Revisão de literatura e fontes para estudo das ONGs podem ser encontradas em Clarke, Gerard. "Non-Governmental Organizations (NGOs) and Politics in the Developing World". Political Studies, 1998, march, XLVI-1; também em Alger, Chadwick. "Strengthening Relations between NGOs and the UN System: towards a Research Agenda". Global Society, vol. 13, n. 4, october 1999. As relações entre ONGs e Banco Mundial são discutidas em Williams, David e Young, Tom. "Governance, the World Bank and Liberal Theory". Political Studies, 1994, march, XLII-1.

29 Emblema desse enfoque está na coletânea organizada por John Cavanagh, Beyond Bretton Woods (1994). Veja-se, entre outros, o artigo de Richard Barnet e Cavanagh, sobre um "Global New Deal". Cf. ainda, de Lance Taylor e John Eatwell, Global Finance at Risk (2000).

30 Cf. especialmente os capítulos 10 (sobre a comunidade política e a ordem cosmopolita) e 12 (sobre a democracia cosmopolita e a nova ordem internacional). O livro de Held é resenhado por Goldblatt, David na New Left Review, 225, sept-october 1997. Outras discussões desse tema, com indicação de novas fontes e enfoques são encontradas em: Linch. 2000; Zürn, 2000; Coleman e Porter, 2000; Cox, 1999; Cortell e Davis Jr., 2000. 


\section{REFERÊNCIAS BIBLIOGRÁFICAS}

ALGER, Chadwick. "Strengthening relations between NGOs and the UN system: towards a research agenda". Global Society - Journal of Interdisciplinary International Relations, vol. 13, n. 4, october 1999.

ARRIGHI, Giovanni. O longo século XX-dinheiro, poder e as origens de nosso tempo. São Paulo. Editora Unesp/Contraponto, 1996

ASSMAN, Hugo. A trilateral ñ nova fase do capitalismo mundial. Rio de Janeiro. Ed. Vozes, 1979.

BATISTA JR., Paulo Nogueira. A economia como ela é. São Paulo. Ed. Boitempo, 2000.

BERGER, Suzanne and Dore, Ronald (eds.). National Diversity and Global Capitalism. Ithaca and London. Cornell University Press, 1996.

BLOCK, Fred. Los orígenes del desorden económico internacional. Mexico. Fondo de Cultura Económica, 1980.

"Contradictions of Self-Regulating Markets. in Mendel, Marguerite and Salée, Daniel (eds.) The Legacy of Karl Polanyi - Market, State and Society at the End of the Twentieth Century. London. MacMillan, 1991.

BOYER, Robert Boyer e J. Rogers Hollingsworth. "Coordination of economic actors and social systems of production”. in Hollingsworth e Boyer (eds.) Contemporary Capitalism - the Embeddedness of Institutions. Cambridge University Press, 1997.

CAVANAGH, John. Beyond Bretton Woods - Alternatives to the Global Economic Order. London. Pluto Press/Institue for Policy Studies/Transnational Institute, 1994.

CLARKE, Gerard. "Non-Governmental Organizations (NGOs) and Politics in the Developing World", Political Studies, 1998, march, XLVI-1

COASE, Ronald. La empresa, el mercado y la ley. Madrid, Alianza Editorial, 1994.

COCKETT, Richard. Thinking the Unthinkable - Think-tanks and the Economic Counter-revolution (1931-1983). London. Harper Collins Publishers, 1995.

COHEN, Benjamin. "Phoenix Risen: the Ressurrection of Global Finance". in World Politics, 1996, january, v. 48, n. 2;

COLEMAN, William e Porter, Tony. "International Institutions, Globalization and Democracy: Assessing the Challenges". Global Society - Journal of Interdisciplinary International Relations, vo. 14, n. 3, july 2000;

CORTELL, Andrew \& Davis Jr., James. "Understanding the Domestic Impact of International Norms: a Research Agenda”. International Studies Review, vol. 2, issue 1, spring 2000.

COX, Robert. "Civil Society at the Turn of the Millenium: Prospects for an Alternative World Order”. Review of International Studies, vol. 25, n. 1, january 1999;

CROZIER, M. , Huntington, S. e Watanuki, J.. The crisis of democracy. New York University Press, 1975.

DAHL, Robert. Dillemas of Pluralist Democracy - Autonomy vs. Control. New Have/London. Yale University Press, 1982.

DAVID Held. Democracy and the Global Order - from the Modern State to Cosmopolitan Governance. London. Polity Press, 1995.

EICHENGREEN, Barry - A globalização do capital: uma história do sistema monetário internacional. São Paulo. Ed. 34, 2000.

GALBRAITH, John Kenneth. O novo Estado industrial. São Paulo. Ed. Nova Cultural, 1984.

GOLDBLATT, David. "At the Limits of Political Possibility: the Cosmopolitan Democratic Project". New Left Review, 225, sept-october 1997.

GOODMAN, John B. e Pauly, Louis. "The Obsolescence of Capital Controls? Economic Management in an Age of Global Markets". World Politics, 1993, october, v. 46, n. 1. 
GRAY, John. Beyond the New Right-Markets, Government and the Common Environment. London/NewYork. Routledge, 1993.

----- Endgames - Questions in Late Modern Political Thought. Cambridge. Polity Press, 1997.

----- Falso amanhecer - os equívocos do capitalismo global. Rio de Janeiro. Ed. Record, 1999

GREIDER, William. One World, Ready or not - the Manic Logic of Global Capitalism. New York. Touchstone/Simon \& Schuster, 1998.

"The Global Marketplace: a Closet Dictator". in R. Nader et al. The Case Against Free Trade. San Francisco. Earth Island Press, 1993.

HELLEINER, Eric. States and the reemergence of global finance-from Bretton Woods to the 1990s. Ithaca and London. Cornell University Press, 1994.

HIRST, Paul. Associative Democracy - New Forms of Economic and Social Governance. Amherst. University of Massachusetts Press, 1994

----- From Statism to Pluralism - Democracy, Civil Society and Global Politics. London. UCL Press, 1997.

HIRST e Khilnani (eds.): Reinventing Democracy, número especial do Political Quarterly, 1996 (Blackwell Publishers).

HIRST, P. e Thompson, G. . Globalização em questão. Petrópolis. Ed. Vozes, 1999.

HODGSON, Geoffrey. Economics and Institutions - a Manifesto for a Modern Institutional Economics. Philadelphia. University of Pensylvania Press, 1988.

HOLLINGSWORTH, J. Rogers and Boyer, Robert. "From National Embeddedness to Spatial and Institutional Nestedness". in Hollingsworth e Boyer, 1997.

HOLLINGSWORTH, J. Rogers and Boyer, Robert. "Coordination of Economic Actors and Social Systems of Production", in Hollingsworth e Boyer, 1997.

HOLlingSWORTH, R. e Boyer, R. (eds.). Contemporary Capitalism - the embeddedness of institutions. Cambridge University Press, 1997.

KEYNES, J. M. . "National Self-sufficiency" [The New Statesman and Nation, 1933. (Reimpresso nos Collected Writings, Cambridge University Press, vol. XXI. pp. 233-246)].

KRUEGER, Anne. Political Economy of Policy Reform in Developing Countries. Massachusetts Institute of Technology, 1993.

"The Political Economy of the Rent-Seeking Society". American Economic Review, june 1974, n. 64. - reeditado na coletânea organizada por J. Buchanan, R.D.Tollison e G. Tullock, Toward a Theory of the Rent-Seeking Society (College Station, Texas A\&M Press, 1980).

LANDAUER, Carl. Sistemas econômicos contemporâneos. R. Janeiro. Ed. Zahar, 1966.

LAZONICK, William. Business Organization and the Myth of the Market Economy. Cambridge University Press, 1991.

LECHNER, Noberto. "Tres formas de coordinación social”. Revista de la Cepal, 1997, abril. LINCH, Marc. "Globalization and International Democracy". International Studies Review, v. 2, issue 3, 2000;

NASH, George. The Conservative Intellectual Movement in America. Intercollegiate Studies Institute, Wilmington/Delaware, 1996

OFFE, Claus. "El corporativismo como um sistema de estructuracion global, no político, de la sociedade?" La gestión política, Coleccion Ediciones de la Revista de Trabajo - Ministerio de Trabajo y Seguridad Social, Madrid, 1992.

----- "Democracia partidária competitiva e o 'Welfare State' keynesiano: fatores de estabilidade e desorganização". em Offe, C., Problemas Estruturais do Estado Capitalista. Rio de Janeiro. Ed. Tempo Brasileiro, 1984

---- Capitalismo desorganizado - transformações contemporâneas do trabalho e da política. São Paulo. Ed. Brasiliense, 1989. 
"A 'ingovernabilidade': sobre o renascimento das teorias conservadoras da crise" (1979). (Reimpresso em Offe, C. , Problemas estruturais do Estado capitalista. Rio de Janeiro. Ed. Tempo Brasileiro, 1984).

ORLÉAN, André (ed.). Analyse économique des conventions. Paris. PUF, 1994.

ORLÉAN, André. Le pouvoir de la finance. Paris. Éditions Odile Jacob, 1999.

PIRENNE, Henri. "The Stages in the Social History of Capitalism," American Historical Review (1914). (Republicado em Bendix, R. e Lipset, S.M. (ed) Class, Status and Power. Glencoe. The Free Press, 1961.

SEERS, Dudley. "Os limites do caso especial" [Publicado pela primeira vez no Boletim do Oxford Institut of Economics and Statistics, da Universidade de Oxford, edição de Basil Blackwell Publisher (n.o 25, 2, Maio de 1963). Tradução de Paula Lima e Artur J. Castro Neves para a Revista de História \& Idéias, Ed. Afrontamento, Porto, 1978, n. II.]

SHONFIELD, Andrew. Capitalismo Moderno. Rio de Janeiro. Ed. Zahar, 1969.

SMITH, James Allen. The Idea Brokers ñ Think Tanks and the Rise of the New Policy Elite. New York/Toronto. The Free Press/Macmillan, 1991.

STIGLITZ, Joseph. "O pós-Consenso de Washington". Folha de S. Paulo, 12/Jul/98, Caderno Mais!

---- "O que eu aprendi com a crise mundial". Folha de S.Paulo, 15 de abril de 2000 (artigo publicado originalmente em The New Republic).

"Mas instrumentos y metas mas amplias para el desarrollo". Desarrollo Económico, 1998 oct-diciembre, v. 38 , n. 151, pp. 691-722

"Participation and Development - Perspectives from the Comprehensive Development Paradigm - Remarks at the International Conference on Democracy, Market Economy and Development". Seoul, Korea, February 27, 1999. (Texto disponível no website do World Bank - www.worldbank.org).

STRANGE, Susan. Mad Money - when Markets Outgrow Governments. The University of Michigan Press, 1998.

TAYLOR, Lance e John Eatwell. Global Finance at Risk - the Case for International Regulation. New York. The New Press, 2000.

LOWI , Theodore. The End of Liberalism - Ideology, Policy, and the Crisis of Public Authority. New York. W. W. Norton \& Co., 1969.

WADE, Robert. "Globalization and its Limits: Reports of the Death of the National Economy are Greatly Exaggerated". em Berger, Suzanne and Dore, Ronald (eds.) National Diversity and Global Capitalism. Ithaca and London. Cornell University Press, 1996.

WEISS, Linda. "Globalization and the Myth of the Powerless State". New Left Review, 1998.

WILLIAMS, David e Young, Tom. "Governance, the World Bank and Liberal Theory". Political Studies, 1994, march, XLII-1.

WILLIAMSON, Oliver. Las instituciones económicas del capitalismo. México. Ed. Fondo de Cultura Económica, 1989

----- Mercados y jerarquías: su análisis y sus implicaciones antitrust. México. Ed. Fondo de Cultura Económica, 1991.

WILLIAMSON, Oliver e Winter, Sydney (orgs.) La naturaleza de la empresa - orígenes, evolución y desarrollo. México. Ed. Fondo de Cultura Económica, 1996.

ZÜRN, Michael. "Democratic Governance beyond the Nation-state: the EU and other International Institutions". European Journal of International Relations, v. 6, n. 2 , june 2000 . 


\title{
RESUMOS/ABSTRACTS
}

\section{ESTADO, MERCADO E OUTRAS INSTITUIÇÕES REGULADORAS}

\author{
REGINALDO MORAES.
}

Examinam-se transformações recentes no papel, dimensões, forma e relevância do Estado nacional, no quadro da chamada globalização. Isso é feito mediante a construção de três eixos analíticos. O primeiro deles contempla a redefinição da "forma-Estado". O segundo aponta para os vínculos entre instituições sociais e instâncias políticas de representação e decisão. $\mathrm{O}$ terceiro enfatiza a dimensão necessariamente internacional das formas políticas de organização que podem ou devem ser pensadas para enfrentar a complexidade das relações entre instituições políticas e inovações econômicas.

Palavras-chave: Estado; mercado; instituições políticas; inovação econômica

\section{STATE, MARKET, AND OTHER REGULATORY INSTITUTIONS}

Recent transformations of the role, dimensions, forms and relevance of the national State in the framework of the so-called globalization are examined. This is done through the building of three analytical axis. The first one regards the redefin ition of the "State form". The second one points toward the links between social institutions and political organs of representation and decision. The third one focuses on the necessarily international dimension of the political forms of organ ization which may or ought to be conceived in order to face the complexity of the relationships between political institutions and economic innovations.

Keywords: State; market; political institutions; economic innovation. 